\title{
Outcomes of early surgery for infective endocarditis with moderate cerebral complications
}

Ryosuke Murai, MD, ${ }^{a}$ Shunsuke Funakoshi, MD, ${ }^{a}$ Shuichiro Kaji, MD, PhD, ${ }^{a}$ Takeshi Kitai, MD, PhD, Kitae Kim, MD, ${ }^{\mathrm{a}}$ Tadaaki Koyama, $\mathrm{MD}, \mathrm{PhD},{ }^{\mathrm{b}}$ and Yutaka Furukawa, MD, $\mathrm{PhD}^{\mathrm{a}}$

\section{ABSTRACT}

Objectives: We sought to clarify the effect of stroke severity on clinical outcomes in patients with infective endocarditis (IE) with cerebral complications and evaluate the impact of early surgery in the active phase on long-term prognosis in patients with nonsevere neurologic deficits.

Methods: Clinical data were reviewed retrospectively in 170 consecutive patients with active left-sided IE with cerebral complications from 1990 to 2014. The mean age was $60 \pm 17$ years, and $93(55 \%)$ were men. The National Institutes of Health Stroke Scale (NIHSS) was used to evaluate the severity of stroke. Major adverse cardiac events were defined as a composite of IE-related death, repeat surgery, and recurrence of IE.

Results: Baseline NIHSS score was associated strongly with clinical outcome. When patients were divided into 2 groups according to NIHSS, 33 patients had severe stroke (NIHSS $\geq 11$ ) and 137 had nonsevere stroke (NIHSS $\leq 10$ ); freedom from IE-related death and major adverse cardiac events was significantly lower in patients with severe stroke than in those with nonsevere stroke. Of 137 patients with nonsevere stroke, 65 underwent early surgery within 2 weeks of onset, and conventional treatment was applied in 72. Freedom from IE-related death was significantly greater in patients undergoing early surgery than in those on conventional treatment $(P=.007)$. Moreover, adjusted survival analysis using the inverse probability treatment weighting method showed a significant beneficial effect of early surgery in reducing IE-related death $(P=.012)$ in patients with nonsevere stroke.

Conclusions: Early surgery might be beneficial in patients with nonsevere stroke. (J Thorac Cardiovasc Surg 2017;153:831-40)

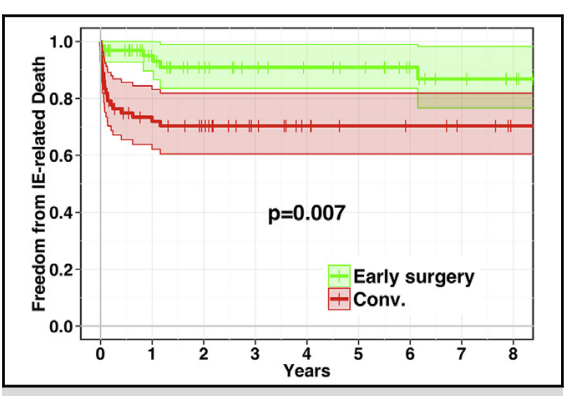

Survival curves free from infective endocarditisrelated death in patients with nonsevere stroke.

\section{Central Message}

Stroke severity is associated strongly with clinical outcomes in patients with infective endocarditis, and early surgery might be beneficial in those patients with nonsevere stroke.

\section{Perspective}

When and for whom surgical intervention should be undertaken for patients with infective endocarditis with cerebral complications remains controversial. Considering the poor clinical outcome of patients with infective endocarditis with severe stroke, the treatmen strategy for each of these patients should be customized according to their condition. Early surgery, however, might be beneficial in patients with nonsevere stroke.

See Editorial Commentary page 841
Cerebral complications occur in $20 \%$ to $40 \%$ of patients during the active course of infective endocarditis (IE) and can be associated with poor clinical outcomes. ${ }^{1-6}$ Surgical intervention is effective for selected patients with IE who

\footnotetext{
From the Departments of ${ }^{\mathrm{a}}$ Cardiovascular Medicine and ${ }^{\mathrm{b}}$ Cardiovascular Surgery, Kobe City Medical Center General Hospital, Kobe, Japan.

Funded by the Department of Cardiovascular Medicine at Kobe City Medical Center General Hospital.

Drs Ryosuke Murai and Shunsuke Funakoshi contributed equally to the study.

Received for publication Feb 23, 2016; revisions received Oct 16, 2016; accepted for publication Oct 25, 2016; available ahead of print Dec 14, 2016.

Address for reprints: Shuichiro Kaji, MD, PhD, Department of Cardiovascular Medicine, Kobe City Medical Center General Hospital, 2-1-1 Minatojimaminamimachi, Chuo-ku, 650-0047 Kobe, Japan (E-mail: skaji@theia.ocn.ne.jp). $0022-5223$

Copyright (C) 2016 by The American Association for Thoracic Surgery. Published by Elsevier Inc. This is an open access article under the CC BY-NC-ND license (http:// creativecommons.org/licenses/by-nc-nd/4.0/).

http://dx.doi.org/10.1016/j.jtcvs.2016.10.074
}

have cerebral complications. When and for whom surgical intervention should be undertaken is controversial because the risk of secondary neurologic exacerbation related to cardiopulmonary bypass is thought to be substantial. Several studies, however, have reported that the risk for deterioration of cerebral complications during cardiac operations, even in the acute phase of cerebral complications, might be lower than estimated previously. $^{7,8}$ In contrast, previous studies showed that

Scanning this QR code will take you to the supplemental tables, figure, video, and appendix for this article. 


\section{Abbreviations and Acronyms \\ $\mathrm{CT}=$ computed tomography \\ IE = infective endocarditis \\ IPTW = inverse probability treatment weighting \\ MACE $=$ major adverse cardiac events \\ MRI = magnetic resonance imaging \\ NIHSS $=$ National Institutes of Health Stroke Scale}

early surgery during initial hospitalization ${ }^{4}$ or within 2 weeks after the diagnosis ${ }^{9}$ was associated with clinical benefits in patients with IE. The effect of early surgery for active IE with cerebral complications on clinical and neurologic outcomes, however, has not been clarified. Moreover, which patients should undergo early surgery remains a conundrum.

In previous studies reporting that abnormal mental status is a strong predictor of mortality in patients with IE, authors used the Glasgow Coma Scale for the evaluation of neurologic deficits. ${ }^{2,10}$ The National Institutes of Health Stroke Scale (NIHSS), a 15-item tool based on neurologic examination, has been used to evaluate the severity of stroke in detail. $^{11,12}$ The NIHSS, however, has not been used for evaluation of IE-related stroke. To identify precisely the effect of stroke severity on clinical outcomes, the evaluation of the degree of neurologic deficit using the NIHSS may be crucial. We hypothesized that stroke severity is associated strongly with clinical outcomes and that the treatment strategy should be designed individually according to severity. Moreover, early surgery might be beneficial in patients with IE with nonsevere stroke. Therefore, the present study aimed to clarify the effect of stroke severity on clinical outcomes in patients with IE with cerebral complications and to evaluate the impact of early surgery in the active phase on long-term prognosis in patients with nonsevere neurologic deficits.

\section{METHODS}

\section{Study Population and Clinical Data}

From 1990 to 2014, a total of 365 patients with active left-sided IE were admitted to our institution. Possible and definite IE were defined with the modified Duke criteria, ${ }^{13,14}$ and episodes that were recorded before 1994 were evaluated retrospectively according to these criteria. A total of 263 $(72 \%)$ patients underwent computed tomography (CT) and/or magnetic resonance imaging (MRI), which revealed that 170 patients were diagnosed as having stroke including cerebral infarction and cerebral hemorrhage. Patients who had only meningitis or encephalopathy without stroke were excluded. The diagnosis of stroke was confirmed by CT and/or MRI. Stroke was diagnosed simultaneously with the diagnosis of IE in $60(35 \%)$ patients (31 symptomatic and 29 asymptomatic patients). Stroke also was diagnosed previously in $42(25 \%)$ patients (38 symptomatic and 4 asymptomatic patients) at a median of 3 days before diagnosis of IE and diagnosed later in $68(40 \%)$ patients (22 symptomatic and 46 asymptomatic patients) at a median of 3 days after diagnosis of IE. As a result, $91(54 \%)$ patients had symptoms of stroke and $79(46 \%)$ patients were asymptomatic. In this study, hemorrhagic infarction was considered separately and differentiated from primary cerebral hemorrhage by radiologists and neurologists.

Using medical records, we extracted data on comorbidities, previous heart disease, isolated micro-organisms, manifestations of IE, the timing and type of cardiac surgery, logistic European System for Cardiac Operative Risk Evaluation, ${ }^{15}$ and clinical outcomes. The NIHSS score was assessed prospectively and retrospectively from a chart review as reported previously. ${ }^{16-18}$ In this study, it was assessed prospectively by neurologists in $18(11 \%)$ patients and retrospectively in $152(89 \%)$ patients. The NIHSS score was evaluated at the onset of stroke in symptomatic patients or when patients were diagnosed as having stroke with CT and MRI in asymptomatic patients. Neurologic recovery was assessed with the modified Rankin Scale, a scale commonly used for measuring the degree of disability or dependence in daily activities. ${ }^{19}$ In this study, a modified Rankin Scale of 0 or 1 was defined as full neurologic recovery, as previously described. ${ }^{20}$

With regard to treatment strategy, early surgery was defined as surgical intervention within 14 days ( 2 weeks) after the initial diagnosis of IE (early surgery group) and conventional treatment was defined as initial antibiotic therapy without early surgery (conventional treatment group). ${ }^{9}$ Late surgery was defined as surgical intervention later than 14 days after the initial diagnosis of IE. The timing of surgery was based on the decision of the attending physician. The indications for valve surgery were heart failure unresponsive to medical therapy, persistent infection, repeat embolization, high embolic risk, and the presence of perivalvular extension of IE. Late surgery was indicated in patients undergoing conventional treatment because of residual severe regurgitation after the resolution of infection.

This study was approved by the institutional review board of Kobe City Medical Center General Hospital. Waiver of informed consent was obtained because of the nature of the study.

\section{Clinical Outcomes}

All of the patients were followed up at the outpatient clinic every 4 to 8 weeks after discharge. Further follow-up was performed by the referring physician. A total of $38(22 \%)$ patients could not be contacted and were lost to follow-up. The mean follow-up period was $4.3 \pm 5.3$ years $(732$ patient-years). Comparison of patient characteristics between patients who were lost to follow-up and those who completed follow-up are shown in Table E1.

In-hospital outcomes, including neurologic and long-term clinical outcomes, such as IE-related death and major adverse cardiac events (MACE), were evaluated. MACE were defined as a composite of IE-related death, repeat surgery, and recurrence of IE during follow-up. IE-related death included cardiac death and death caused by complications of IE while excluding death obviously unrelated to IE (eg, death from malignant disease).

\section{Statistical Analysis}

Categorical variables were compared with the $\chi^{2}$ test or Fisher exact test. Continuous variables are presented as mean \pm standard deviation, except for operative days and survival rates (mean \pm standard error), and were compared by the use of unpaired $t$ tests. Because operative days after onset were not normally distributed, a Mann-Whitney $U$ test was performed to assess differences.

To reduce selection bias and potential confounding in an observational study, we performed rigorous adjustment for differences in baseline characteristics of patients using propensity scores and inverse probability treatment weighting (IPTW). ${ }^{21}$ Propensity scores were defined as the probability that patients would be selected for an early surgical procedure conditional on the measured baseline covariates. Details of the analyses were described in Appendix E1.

Survival analysis was performed by Kaplan-Meier analysis, and differences in survival between groups were examined with the log-rank test. Adjusted survival curves were constructed by use of the IPTW approach 
TABLE 1. Effect of baseline NIHSS score on modified Rankin scale at discharge

\begin{tabular}{|c|c|c|c|c|c|}
\hline & \multicolumn{5}{|c|}{ NIHSS score } \\
\hline & $0-3(n=109)$ & $4-10(n=28)$ & $11-15(n=9)$ & $16-22(n=11)$ & $>22(n=13)$ \\
\hline $\begin{array}{l}\text { Modified Rankin scale } 0-1 \\
\text { (no symptoms or no significant disability) }\end{array}$ & $83(76)$ & $7(25)$ & $2(22)$ & $0(0)$ & $2(15)$ \\
\hline $\begin{array}{l}\text { Modified Rankin scale } 2-3 \\
\text { (slight or moderate disability) }\end{array}$ & $6(6)$ & $5(18)$ & $0(0)$ & $0(0)$ & $0(0)$ \\
\hline $\begin{array}{l}\text { Modified Rankin scale } 4-5 \\
\text { (moderately severe or severe disability) }\end{array}$ & $11(10)$ & $5(18)$ & $2(22)$ & $5(45)$ & $3(23)$ \\
\hline Modified Rankin scale 6 (death) & $9(8)$ & $11(39)$ & $5(56)$ & $6(55)$ & $8(62)$ \\
\hline Hazard ratio for MACE & Reference & $2.24(1.19-4.22)$ & $3.61(1.40-9.32)$ & $4.21(1.82-9.73)$ & $7.25(3.42-15.37)$ \\
\hline Hazard ratio for IE-related death & Reference & $3.56(1.73-7.34)$ & $6.46(2.37-17.59)$ & $6.23(2.55-15.19)$ & $7.23(3.07-17.04)$ \\
\hline
\end{tabular}

NIHSS, National Institutes of Health Stroke Scale; MACE, major adverse cardiac events; IE, infective endocarditis.

from Cole and Hernan. ${ }^{22}$ Two-sided $P$ values of less than .05 were considered to be significant for all analyses. All statistical analyses were performed with SPSS software (version 17.0; SPSS Inc, Chicago, Ill) or R software packages, version 3.3.0 (R Development Core Team, Vienna, Austria).

\section{RESULTS}

\section{Baseline NIHSS Score and Clinical Outcome}

Table 1 shows the effect of the baseline NIHSS score on the modified Rankin Scale at discharge and IE-related surgery. The baseline NIHSS score strongly predicted shortand long-term outcomes. The results of the subdistribution hazard model considering death and surgical intervention as competing risks are shown in Appendix E1. A total of 29 $(88 \%)$ of 33 patients who had an NIHSS score $\geq 11$ had a poor clinical outcome (modified Rankin Scale $\geq 4$ ) regardless of the treatment strategy. A total of $102(74 \%)$ of 137 patients who had an NIHSS score $\leq 10$ achieved an excellent or good outcome (modified Rankin scale $\leq 3$ ). In addition, the hazard ratio for IE-related death was increased in patients who had an NIHSS score $\geq 11$. According to these findings, we divided patients into 2 groups based on the NIHSS score: severe stroke (NIHSS score $\geq 11$ ) and nonsevere stroke (NIHSS score $\leq 10$ ).

Figure 1 shows the flow diagram for the patients in the 2 groups. Of the 170 patients, $33(19 \%)$ had severe stroke

\section{Patient Flow}

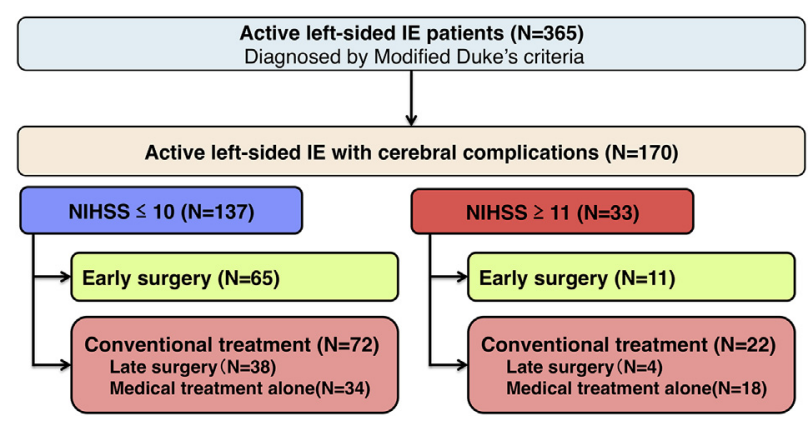

FIGURE 1. Diagram showing initial treatment modalities for all patients. $I E$, Infective endocarditis; NIHSS, National Institutes of Health Stroke Scale.
(NIHSS $\geq 11)$ and $137(81 \%)$ had nonsevere stroke (NIHSS $\leq 10)$. In patients with severe stroke, $11(33 \%)$ underwent early surgery and $22(67 \%)$ received conventional treatment. Of the 137 patients with nonsevere stroke, $65(47 \%)$ underwent early surgery (Video 1 ) and $72(53 \%)$ received conventional treatment. Among the patients who received conventional treatment, $38(53 \%)$ patients underwent late surgery and the other $34(47 \%)$ received medical treatment alone. As a result, $76(45 \%)$ patients underwent early surgery and $42(25 \%)$ patients underwent late surgery (41 patients during the initial hospitalization). Late surgery was indicated in $33(79 \%)$ patients because of persistent infection and in $7(17 \%)$ patients for recurrent embolic events. The remaining patients had late surgery because of severe regurgitation after the resolution of infection. Table 2 shows the baseline characteristics and clinical outcomes in patients with severe and nonsevere stroke. In-hospital mortality

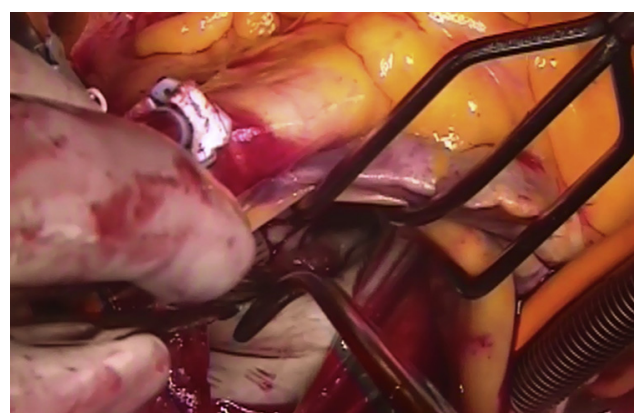

VIDEO 1. A 77-year-old man was admitted to our hospital with 2-week history of persistent fever and transient paralysis of right arm. Serial sets of blood culture were positive for Streptococcus mitis. Magnetic resonance imaging of the brain revealed multiple acute cerebral infarcts. Transthoracic echocardiography revealed large vegetation on the mitral valve. $\mathrm{He}$ was diagnosed as having infective endocarditis and underwent mitral valve repair and coronary artery bypass grafting 10 days after the diagnosis. His postoperative course was uneventful, and he was discharged without any neurologic deficit. Video available at: http://www.jtcvsonline.org/article/ S0022-5223(16)31481-7/addons. 
TABLE 2. Characteristics and clinical outcomes of patients with IE complicating stroke

\begin{tabular}{|c|c|c|c|}
\hline & NIHSS $\leq 10(n=137)$ & NIHSS $\geq 11(n=33)$ & $\boldsymbol{P}$ \\
\hline \multicolumn{4}{|l|}{ Background } \\
\hline Age, $y$, mean $\pm S D$ & $59 \pm 17$ & $64 \pm 17$ & .140 \\
\hline Male, n (\%) & $78(57)$ & $15(46)$ & .234 \\
\hline $\mathrm{DM}, \mathrm{n}(\%)$ & $22(16)$ & $5(15)$ & .898 \\
\hline Renal failure $(\mathrm{Cr}>2.0 \mathrm{mg} / \mathrm{dL}), \mathrm{n}(\%)$ & $26(19)$ & $5(15)$ & .609 \\
\hline Dialysis, n (\%) & $15(11)$ & $2(6)$ & .401 \\
\hline History of IE, n (\%) & $11(8)$ & $2(6)$ & .734 \\
\hline \multicolumn{4}{|l|}{ Vegetation site } \\
\hline Aortic, n (\%) & $58(42)$ & $15(46)$ & .745 \\
\hline Mitral, n (\%) & $99(72)$ & $27(82)$ & .261 \\
\hline Aortic and mitral, n (\%) & $23(17)$ & $9(27)$ & .167 \\
\hline PVE, n (\%) & $23(17)$ & $5(15)$ & .820 \\
\hline Vegetation $>10 \mathrm{~mm}, \mathrm{n}(\%)$ & $89(65)$ & $23(70)$ & .607 \\
\hline Abscess, n (\%) & $24(18)$ & $4(12)$ & .453 \\
\hline \multicolumn{4}{|l|}{ Pathogens } \\
\hline Streptococcus spp., $\mathrm{n}(\%)$ & $58(42)$ & $8(24)$ & .056 \\
\hline Staphylococcus spp., n (\%) & $43(31)$ & $10(30)$ & .904 \\
\hline \multicolumn{4}{|l|}{ Cerebral complication } \\
\hline Cerebral infarction, $\mathrm{n}(\%)$ & $100(73)$ & $25(76)$ & .747 \\
\hline Symptomatic CI, n (\%) & $50(37)$ & $25(76)$ & $<.001$ \\
\hline Hemorrhagic CI, n (\%) & $9(7)$ & $2(6)$ & .915 \\
\hline Cerebral hemorrhage, $\mathrm{n}(\%)$ & $50(37)$ & $15(45)$ & .342 \\
\hline Symptomatic ICH, n (\%) & $13(9)$ & $15(45)$ & $<.001$ \\
\hline Brain abscess, $\mathrm{n}(\%)$ & $12(9)$ & $1(3)$ & .266 \\
\hline NIHSS, median (IQR) & $0(0-3)$ & $19(14-30)$ & $<.001$ \\
\hline $0-3$ points & $109(80)$ & & \\
\hline 4-10 points & $28(20)$ & & \\
\hline $11-15$ points & & $9(27)$ & \\
\hline $16-22$ points & & $11(33)$ & \\
\hline $22-42$ points & & $13(39)$ & \\
\hline \multicolumn{4}{|l|}{ Others } \\
\hline EuroSCORE logistic, $\%$, median (IQR) & $11.3(5.8-27.7)$ & $30.3(17.9-42.6)$ & $<.001$ \\
\hline \multicolumn{4}{|l|}{ Operations } \\
\hline Operation during initial admission, $\mathrm{n}(\%)$ & $102(74)$ & $15(45)$ & .001 \\
\hline Operative timing, ${ }^{*} \mathrm{~d}$, median (IQR) & $10(4-27)$ & $4(1-14)$ & .019 \\
\hline Early surgery, n (\%) & $65(47)$ & $11(33)$ & .143 \\
\hline Late surgery, n (\%) & $38(28)$ & $4(12)$ & .062 \\
\hline Postoperative cerebral infarction, n (\%) & $10(10)$ & $0(0)$ & .207 \\
\hline Postoperative cerebral hemorrhage, $\mathrm{n}(\%)$ & $13(13)$ & $4(27)$ & .180 \\
\hline Postoperative neurologic worsening, n (\%) & $21(20)$ & $4(27)$ & .578 \\
\hline Symptomatic neurologic worsening, n (\%) & $11(11)$ & $3(20)$ & .297 \\
\hline \multicolumn{4}{|l|}{ Clinical outcome } \\
\hline In-hospital death, $\mathrm{n}(\%)$ & $19(14)$ & $19(58)$ & $<.001$ \\
\hline After surgery, n (\%) & $6(4)$ & $6(18)$ & .013 \\
\hline After medical treatment alone, $\mathrm{n}(\%)$ & $13(9)$ & $13(39)$ & $<.001$ \\
\hline Modified Rankin scale at discharge, mean $\pm \mathrm{SD}$ & $1.7 \pm 2.3$ & $4.9 \pm 1.8$ & $<.001$ \\
\hline Full neurologic recovery at discharge, $\nmid \mathrm{n}(\%)$ & $90(66)$ & $4(12)$ & $<.001$ \\
\hline All-cause death, n (\%) & $39(28)$ & $22(67)$ & $<.001$ \\
\hline IE-related death, n (\%) & $30(22)$ & $20(61)$ & $<.001$ \\
\hline Recurrence of IE, n (\%) & $8(6)$ & $2(6)$ & .962 \\
\hline Repeat surgery, n (\%) & $11(8)$ & $2(6)$ & .703 \\
\hline
\end{tabular}

$\overline{I E}$, Infective endocarditis; $N I H S S$, National Institutes of Health Stroke Scale; $D M$, diabetes mellitus; $C r$, creatinine; $P V E$, prosthetic valve endocarditis; $C I$, cerebral infarction; $I C H$, intracerebral hemorrhage; IQR, interquartile range; EuroSCORE, European System for Cardiac Operative Risk Evaluation. *Days after onset. $\nmid$ Modified Rankin scale $\leq 1$. 


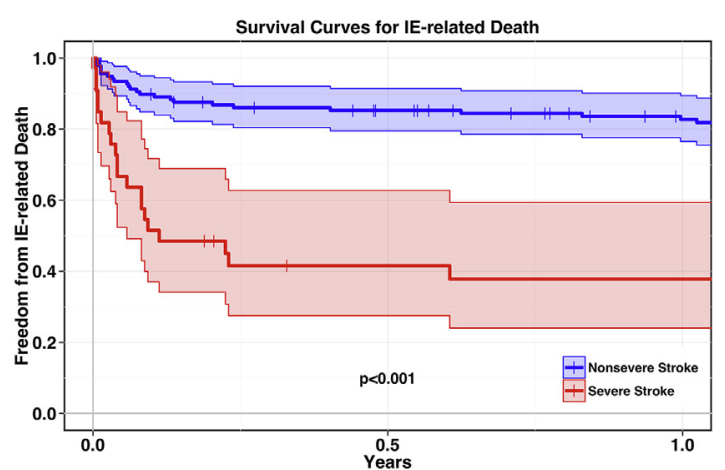

Patients at risk

A Nonsevere Stroke 137

108
11

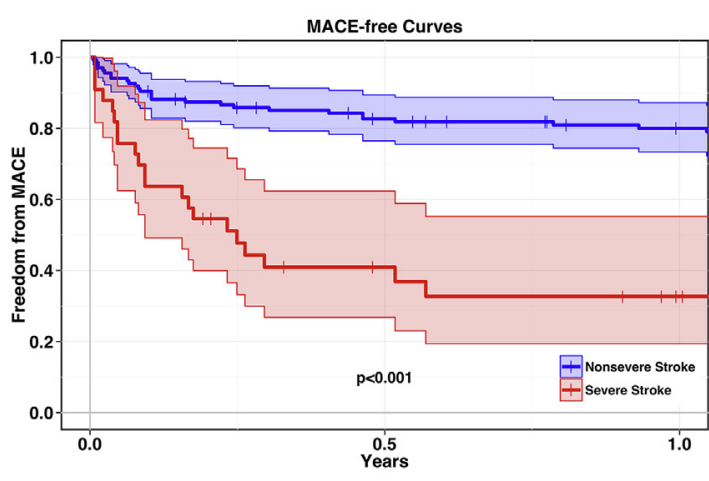

Patients at risk

B Senserese Stroke ${ }_{33}^{137}$

101
10

85
5

FIGURE 2. Comparison of IE-related mortality and MACE between patients with severe stroke and those with nonsevere stroke. A, Survival curves free from IE-related death. B, Survival curves free from MACE. $I E$, Infective endocarditis; $M A C E$, major adverse cardiac events.

$(58 \%$ vs $14 \%, P<.001)$ and the modified Rankin Scale at discharge were significantly greater in patients with severe stroke than in those with nonsevere stroke $(P<.001)$.

Figure 2 shows a comparison of IE-related death and MACE during follow-up periods between patients with severe stroke and those with nonsevere stroke. Freedom from IE-related death and MACE was significantly lower in patients with severe stroke than in those with nonsevere stroke (at 5 years for IE-related death: $38 \% \pm 9 \%$ vs $80 \% \pm 4 \%$, $P<.001$; at 2 years for MACE: $25 \% \pm 10 \%$ vs $73 \% \pm 4 \%$, $P<.001)$.

\section{Effect of Early Surgery on Clinical Outcomes in Patients With Severe Stroke}

In 11 patients with severe stroke who underwent early surgery, $4(36 \%)$ died in the index hospitalization, and 3 $(27 \%)$ were discharged with full neurologic recovery. In 22 patients who received conventional treatment, 15 $(68 \%)$ died in the index hospitalization and $1(5 \%)$ achieved full neurologic recovery at discharge. Unadjusted survival curves free from IE-related death and MACE are shown in Figure 3. There were no significant differences in estimated survival free from IE-related death and
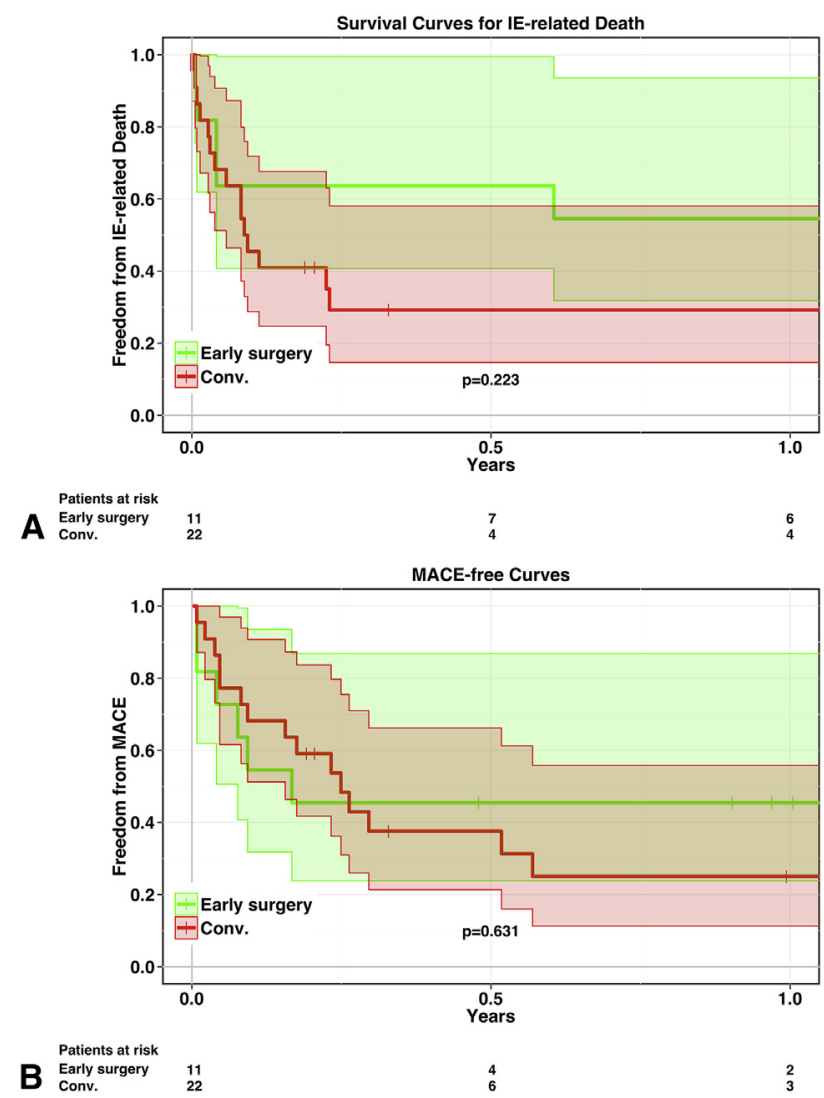

B Early surgery

FIGURE 3. Comparison of IE-related mortality and MACE between early surgery and conventional treatment in patients with severe stroke. A, Survival curves free from IE-related death. B, Survival curves free from MACE. IE, Infective endocarditis; Conv., conventional treatment; MACE, major adverse cardiac events.

MACE between patients with severe stroke undergoing early surgery and those on conventional treatment ( $P=.223$ for IE-related death and $P=.631$ for MACE).

\section{Effect of Early Surgery on Clinical Outcomes in Patients With Nonsevere Stroke}

Baseline characteristics of patients with nonsevere stroke according to treatment strategy are shown in Table 3. Inhospital mortality was significantly lower in patients undergoing early surgery than in those receiving conventional treatment ( $3 \%$ vs $24 \%, P<.001$ ). The modified Rankin Scale at discharge also was significantly lower in patients undergoing early surgery than in those on conventional treatment $(P=.009)$. Unadjusted and adjusted survival curves free from IE-related death or MACE are shown in Figure 4. Freedom from IE-related death was significantly greater in patients undergoing early surgery than in those receiving conventional treatment (at 5 years for IE-related death: $91 \% \pm 3 \%$ vs $70 \% \pm 5 \%, P=.007$, Figure 4 , $A)$. After adjustment with IPTW, patients undergoing early surgery had better survival free from IE-related death than those on conventional treatment (log-rank $P=.012$, 
TABLE 3. Characteristics and clinical outcomes of patients with nonsevere stroke

\begin{tabular}{|c|c|c|c|}
\hline & Early surgery $(n=65)$ & Conventional treatment $(n=72)$ & $P$ \\
\hline \multicolumn{4}{|l|}{ Background } \\
\hline Age, $y$, mean \pm SD & $56 \pm 17$ & $62 \pm 17$ & .037 \\
\hline Male, n (\%) & $40(62)$ & $38(53)$ & .301 \\
\hline $\mathrm{DM}, \mathrm{n}(\%)$ & $7(11)$ & $15(21)$ & .109 \\
\hline Renal failure $(\mathrm{Cr}>2.0 \mathrm{mg} / \mathrm{dL}), \mathrm{n}(\%)$ & $10(15)$ & $16(22)$ & .308 \\
\hline Dialysis, n (\%) & $4(6)$ & $11(15)$ & .088 \\
\hline History of IE, n (\%) & $5(8)$ & $6(8)$ & .890 \\
\hline \multicolumn{4}{|l|}{ Vegetation site } \\
\hline Aortic, n (\%) & $30(46)$ & $28(39)$ & .390 \\
\hline Mitral, n (\%) & $50(77)$ & $49(68)$ & .247 \\
\hline Aortic and mitral, $\mathrm{n}(\%)$ & $15(23)$ & $8(11)$ & .061 \\
\hline PVE, n (\%) & $11(17)$ & $12(17)$ & .968 \\
\hline Vegetation $>10 \mathrm{~mm}, \mathrm{n}(\%)$ & $52(80)$ & $37(51)$ & $<.001$ \\
\hline Abscess, n (\%) & $12(18)$ & $12(17)$ & .783 \\
\hline \multicolumn{4}{|l|}{ Pathogens } \\
\hline Streptococcus spp., n (\%) & $28(43)$ & $30(42)$ & .868 \\
\hline Staphylococcus spp., n (\%) & $19(29)$ & $24(33)$ & .605 \\
\hline \multicolumn{4}{|l|}{ Cerebral complication } \\
\hline Cerebral infarction, $\mathrm{n}(\%)$ & $52(80)$ & $48(67)$ & .079 \\
\hline Symptomatic CI, n (\%) & $20(31)$ & $30(42)$ & .186 \\
\hline Hemorrhagic CI, n (\%) & $3(5)$ & $6(8)$ & .380 \\
\hline Cerebral hemorrhage, n (\%) & $22(34)$ & $28(39)$ & .540 \\
\hline Symptomatic ICH, n (\%) & $4(6)$ & $9(13)$ & .206 \\
\hline Brain abscess, $\mathrm{n}(\%)$ & $4(6)$ & $8(11)$ & .305 \\
\hline NIHSS, median (IQR) & $0(0-2)$ & $0(0-3)$ & .515 \\
\hline $0-3$ points & $53(82)$ & $56(78)$ & .586 \\
\hline 4-10 points & $12(18)$ & $16(22)$ & .586 \\
\hline \multicolumn{4}{|l|}{ Others } \\
\hline EuroSCORE logistic, $\%$, median (IQR) & $11.7(6.0-23.5)$ & $10.8(5.0-31.5)$ & .665 \\
\hline \multicolumn{4}{|l|}{ Operations } \\
\hline Operation during initial admission, $\mathrm{n}(\%)$ & $65(100)$ & $37(51)$ & $<.001$ \\
\hline Operative timing,* d, median (IQR) & $5(2-8.5)$ & $34(22-60) \dagger$ & $<.001$ \\
\hline Postoperative cerebral infarction, $\mathrm{n}(\%)$ & $9(14)$ & $1(3) \dagger$ & .064 \\
\hline Postoperative cerebral hemorrhage, n (\%) & $10(15)$ & $3(8) \dagger$ & .269 \\
\hline Postoperative neurologic worsening, $\mathrm{n}(\%)$ & $17(26)$ & $4(11) \dagger$ & .058 \\
\hline Symptomatic neurologic worsening, $\mathrm{n}(\%)$ & $9(14)$ & $2(5) \dagger$ & .104 \\
\hline \multicolumn{4}{|l|}{ Outcome } \\
\hline In-hospital death, n (\%) & $2(3)$ & $17(24)$ & $<.001$ \\
\hline $\mathrm{mRS}$ at discharge, mean $\pm \mathrm{SD}$ & $1.1 \pm 1.8$ & $2.2 \pm 2.5$ & .009 \\
\hline Full neurologic recovery at discharge $(\mathrm{mRS} \leq 1), \mathrm{n}(\%)$ & $50(77)$ & $40(56)$ & .009 \\
\hline All-cause death, n (\%) & $11(17)$ & $28(39)$ & .004 \\
\hline IE-related death, n (\%) & $7(11)$ & $23(32)$ & .003 \\
\hline Recurrence of IE, n (\%) & $5(8)$ & $3(4)$ & .380 \\
\hline Repeat surgery, n (\%) & $7(11)$ & $4(6)$ & .262 \\
\hline
\end{tabular}

$D M$, Diabetes mellitus; $C r$, creatinine; $I E$, infective endocarditis; $P V E$, prosthetic valve endocarditis; $I C H$, intracerebral hemorrhage; NIHSS, National Institutes of Health Stroke Scale; IQR, interquartile range; EuroSCORE, European System for Cardiac Operative Risk Evaluation; $m R S$, modified Rankin Scale. *Days after onset. $\dagger$ Among patients treated by late surgery $(\mathrm{n}=38)$.

Figure 4, C). Unadjusted and IPTW-adjusted survival curves free from MACE, however, showed a tendency towards greater freedom from MACE in patients who underwent early surgery than in those who received conventional treatment (Figure $4, B$ and $D, P=.082$ and $P=.122$, respectively); however, these differences did not reach statistical significance.

\section{Baseline Characteristics and Clinical Outcomes According to Study Term, Stroke Symptoms, and Timing of Stroke Diagnosis}

Because we analyzed the long-term experience of IE treatment, clinical practice and patients' characteristics might have changed during the study period. Therefore, we divided the study period into 2 terms and assessed the 

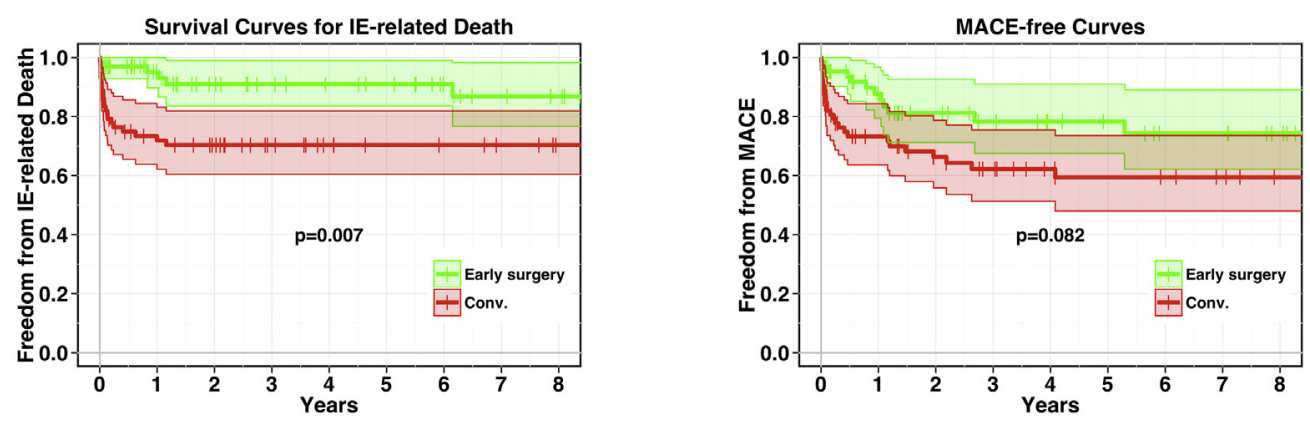

Patients at risk

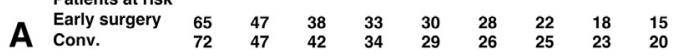

Patients at risk

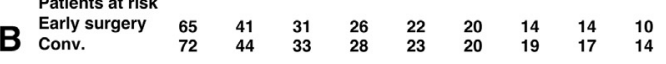
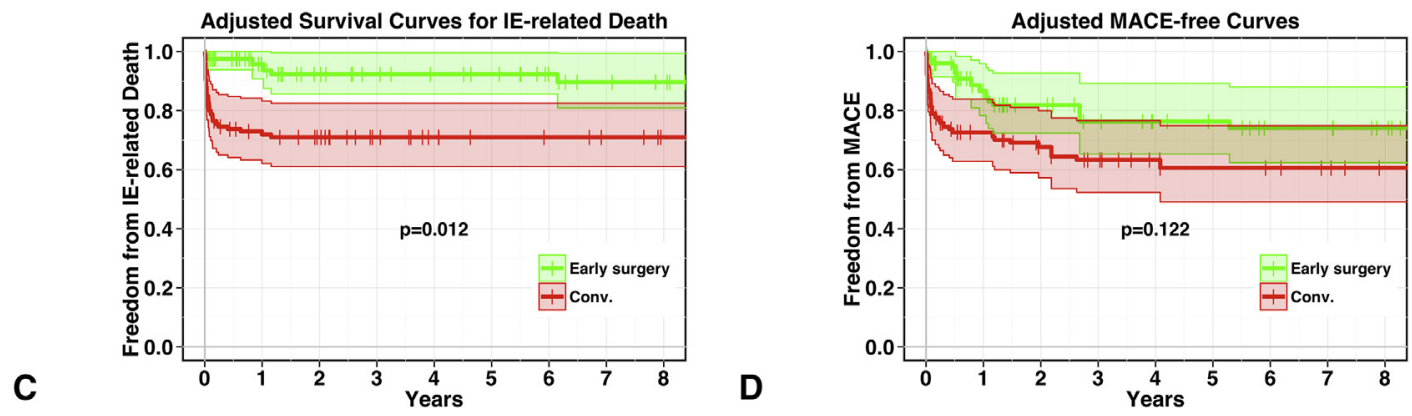

FIGURE 4. Comparison of IE-related mortality and MACE between early surgery and conventional treatment in patients with nonsevere stroke. A, Survival curves free from IE-related death. B, Survival curves free from MACE. C, IPTW-weighted survival curves free from IE-related death. D, IPTWweighted survival curves free from MACE. IE, Infective endocarditis; MACE, major adverse cardiac events; Conv., conventional treatment.

baseline characteristics and outcomes according to these terms (Appendix E1 and Table E2). Table E3 shows the relationships between imaging findings and NIHSS stratifications. In addition, baseline characteristics and clinical outcomes according to stroke symptoms and timing of stroke diagnosis were also shown in the Appendix E1 and Tables E4 and E5.

\section{Agreement of Prospective and Retrospective NIHSS}

We retrospectively analyzed NIHSS score in the 18 patients in whom the NIHSS was assessed prospectively by neurologists. Results are shown in Appendix E1.

\section{Postoperative Clinical Outcomes in Patients With Nonsevere Hemorrhagic Stroke}

Appendix E1 and Table E6 show postoperative adverse events and clinical outcomes in patients with nonsevere stroke according to treatment strategy and hemorrhagic stroke.

\section{Predictors of Poor Modified Rankin Scale at Discharge in Patients With Nonsevere Stroke}

The results of logistic regression analyses of predictors of poor modified Rankin Scale are shown in Appendix E1 and Table E7.

\section{DISCUSSION}

The present study evaluated the clinical outcomes of patients with active IE who had cerebral complications related to stroke severity. The main findings of our study were as follows: (1) patients with active IE complicated by severe stroke (NIHSS score $\geq 11$ ) had a greater rate of IE-related mortality $(P<.001)$ and MACE $(P<.001)$ than those with nonsevere stroke (NIHSS score $\leq 10$ ); (2) in patients with nonsevere stroke, the survival rate free from IErelated death in the early surgery group was significantly greater than that in the conventional treatment group $(P=.007)$; and (3) patients complicated by severe stroke had a poor prognosis, regardless of the treatment strategy. These findings suggest that early surgical intervention within 2 weeks may further improve clinical outcomes, with acceptable mortality and neurologic prognosis in patients with active IE complicated by nonsevere stroke.

There is no recommendation in the current guidelines regarding the management of active IE with cerebral complications. ${ }^{23}$ In particular, which patients should undergo early surgery has not been determined. In the present study, patients with severe neurologic deficits had a poor prognosis regardless of undergoing early surgery. Therefore, the treatment strategy for these patients should be determined according to other clinical conditions of each patient. However, early surgery might be beneficial in IE patients with nonsevere stroke. To clarify this issue, we selected 
patients who had mild-to-moderate neurologic symptoms according to the NIHSS and assessed the impact of early surgery on their clinical outcome.

Early surgery has positive and negative effects on patients with IE with stroke. Cardiac surgery potentially may worsen the neurologic deficit because of complications of cerebral hemorrhage related to heparinization and extension of ischemic lesions related to hypotension during cardiopulmonary bypass. In addition, the risk of embolization on optimal medical therapy is relatively small in appropriately selected patients who have less-aggressive organisms and smaller vegetation when aggressive antibiotic therapy is instituted and appropriate drug concentrations have been obtained.

Several studies, however, have demonstrated that the risk of neurologic exacerbation by early surgery appears to be relatively low. ${ }^{7,8,10}$ The International Collaboration on Endocarditis-Prospective Cohort Study group recently found that there was no apparent survival benefit in delaying surgery in patients with ischemic stroke. ${ }^{24}$ Moreover, another recent study reported that the risk of hemorrhagic transformation of preoperative acute cerebral infarction is low in patients with early surgery. ${ }^{25}$ In the present study, although the incidence of symptomatic neurologic worsening owing to postoperative cerebral infarction and cerebral hemorrhage was not negligible in those who underwent early surgery, the rate of full neurologic recovery at discharge was almost $70 \%$. Therefore, early surgery might not have a negative effect on neurologic prognosis.

With regard to long-term clinical outcomes, unadjusted and IPTW-adjusted survival analysis showed a beneficial effect of early surgery on IE-related death in patients with nonsevere stroke $(P=.007$ and $P=.012$, respectively). These results suggest that early surgery improves clinical outcomes, with acceptable postoperative mortality and neurologic morbidity, in patients with mild-to-moderate neurologic deficits. Although there was a tendency towards a greater rate of freedom from MACE in patients with early surgery than in those receiving conventional treatment, however, these differences did not reach statistical significance in both unadjusted and adjusted survival analysis $(P=.082$ and $P=.122$, respectively). This finding may be attributable partially to greater rates of IE recurrence and repeat surgery in patients undergoing early surgery. Our findings suggested that prolonged postoperative antibiotic therapy and close surveillance might be necessary in patients with nonsevere stroke who have undergone early surgery.

Another clinical issue is the optimal timing of surgical treatment. The risk of embolism has been reported to be greater within 14 days after the initial diagnosis of IE than after 14 days. ${ }^{26,27}$ However, although surgery can reduce the risk of recurrent embolization and worsening of septic conditions and heart failure, immediate surgery after the onset of stroke may cause serious postoperative complications. Thus, previous reports have suggested that surgeons should wait for 14 days to operate on patients after cerebral complications. ${ }^{28,29}$

In contrast, Piper and colleagues ${ }^{7}$ reported that cardiac surgery should be performed within 72 hours of cerebral embolism, when the risk of secondary cerebral hemorrhage appears to be low. Considering these findings, we defined early surgery as surgical intervention within 14 days after the initial diagnosis. Consequently, in patients with nonsevere stroke, although the incidence of postoperative symptomatic neurologic worsening was greater in the early surgery group than in the late surgery group, this difference did not reach statistical significance. The rate of full neurologic recovery at discharge was significantly greater in the early surgery group. These findings suggest that surgical intervention may not need to be delayed until 14 days after the initial diagnosis of IE. Further investigations will be required to clarify the optimal timing of surgical intervention for patients with cerebral complications.

In the present study, we assessed the NIHSS to evaluate the severity of stroke. Previous studies have reported that abnormal mental status is a predictor of mortality using a physician's qualitative evaluation or Glasgow Coma Scale. ${ }^{2,10}$ Mental status is not sufficient, however, for an assessment of stroke severity. The NIHSS is a method for rapid assessment of stroke severity, with excellent reliability, and has been used in many studies..$^{11,12,20,30}$ Moreover, a minimal amount of training is required to reliably administer this tool, even by non-neurologists. ${ }^{11}$ Therefore, we believe that evaluating the level of neurologic deficit by the NIHSS is useful for determining the treatment strategy in patients with IE complicated by stroke.

\section{Study Limitations}

This study has several limitations. First, the inherent limitations of a nonrandomized retrospective study design should be acknowledged. The choice of early surgery was at the discretion of the treating physician. Despite rigorous adjustment for selection bias and confoundings with the IPTW method, hidden biases or residual confounding may have affected the results. In addition, because of the retrospective study design, $38(22 \%)$ patients were lost to follow-up, which may have affected the study results. Patients who were lost to follow-up, however, had comparable clinical characteristics to those who were followed-up. Thus, it is unlikely that the patients lost to follow-up had a greater rate of mortality than those who completed followed-up. Moreover, we did not screen all asymptomatic patients with IE, which may lead to an unintended selection bias. Therefore, large randomized clinical trials with longterm follow-up will be necessary to verify our findings. Second, because the decision of operative timing may change according to the patient's condition, propensity score calculation might be inappropriate. This "survivor treatment 
bias" or "time-dependent bias" occurs because patients who live longer are more likely to receive treatment than patients who die early. ${ }^{31}$ However, to minimize survivor treatment bias, we excluded patients with severe stroke in the IPTW analysis, in whom in-hospital mortality was relatively high, and focused on patients with nonsevere stroke to assess the role of early surgery. In addition, we evaluated the role of early surgery within 14 days after the onset. The term of 2 weeks is shorter than that in previous studies, in which surgery was coded as a binary variable during initial hospitalization. ${ }^{4,32}$ Therefore, the effect of time-dependent bias might be minimized. Third, because our analysis was underpowered to detect significant differences of clinical outcomes in severe stroke patients, the effects of early surgery may not have been evaluated in these patients. Fourth, we retrospectively assessed the NIHSS from a chart review in $152(89 \%)$ patients. Nevertheless, several previous studies have shown that retrospective analysis using the NIHSS correlates well with prospective analysis by neurologists. ${ }^{17,18}$ In addition, when we retrospectively analyzed NIHSS scores in the prospectively analyzed 18 patients, agreement was nearly perfect and retrospective NIHSS scores were not significantly different from prospective NIHSS scores. Therefore, we consider that our approach could be acceptable. Finally, we analyzed a 24 year experience and clinical practice has changed during this time period. CT and MRI were used more frequently in recent years, which leads to more asymptomatic patients identified with these modalities.

\section{Future Directions}

How to customize the treatment strategy in patients with severe stroke is a problem. If operative mortality could be predicted by various factors, including the NIHSS, CT/ MRI findings, and patients' clinical conditions, this could be useful. Further large-scale prospective cohort studies are required to determine how to treat these patients.

\section{CONCLUSIONS}

Considering the poor clinical outcome of patients with IE and severe stroke, the treatment strategy for each of these patients should be customized according to their condition; however, early surgery might be beneficial in patients with nonsevere stroke.

\section{Conflict of Interest Statement}

Authors have nothing to disclose with regard to commercial support.

\section{References}

1. Chu VH, Cabell CH, Benjamin DK Jr, Kuniholm EF, Fowler VG Jr, Engemann J, et al. Early predictors of in-hospital death in infective endocarditis. Circulation. 2004; 109:1745-9.

2. Hasbun R, Vikram HR, Barakat LA, Buenconsejo J, Quagliarello VJ. Complicated left-sided native valve endocarditis in adults: risk classification for mortality. Jama. 2003;289:1933-40.
3. Heiro M, Nikoskelainen J, Engblom E, Kotilainen E, Marttila R, Kotilainen P. Neurologic manifestations of infective endocarditis: a 17-year experience in a teaching hospital in Finland. Arch Intern Med. 2000;160:2781-7.

4. Lalani T, Cabell CH, Benjamin DK, Lasca O, Naber C, Fowler VG Jr, et al. Analysis of the impact of early surgery on in-hospital mortality of native valve endocarditis: use of propensity score and instrumental variable methods to adjust for treatment-selection bias. Circulation. 2010;121:1005-13.

5. Nakatani S, Mitsutake K, Ohara T, Kokubo Y, Yamamoto H, Hanai S, et al. Recent picture of infective endocarditis in Japan-lessons from Cardiac Disease Registration (CADRE-IE). Circulation J. 2013;77:1558-64.

6. Misfeld M, Girrbach F, Etz CD, Binner C, Aspern KV, Dohmen PM, et al. Surgery for infective endocarditis complicated by cerebral embolism: a consecutive series of 375 patients. J Thorac Cardiovasc Surg. 2014;147:1837-44.

7. Piper C, Wiemer M, Schulte HD, Horstkotte D. Stroke is not a contraindication for urgent valve replacement in acute infective endocarditis. $J$ Heart Valve Dis 2001; 10:703-11.

8. Ruttmann E, Willeit J, Ulmer H, Chevtchik O, Hofer D, Poewe W, et al. Neurological outcome of septic cardioembolic stroke after infective endocarditis. Stroke. 2006:37:2094-9.

9. Funakoshi S, Kaji S, Yamamuro A, Tani T, Kinoshita M, Okada Y, et al. Impact of early surgery in the active phase on long-term outcomes in left-sided native valve infective endocarditis. J Thorac Cardiovasc Surg. 2011;142:836-42.e1.

10. Thuny F, Avierinos JF, Tribouilloy C, Giorgi R, Casalta JP, Milandre L, et al Impact of cerebrovascular complications on mortality and neurologic outcome during infective endocarditis: a prospective multicentre study. Eur Heart J. 2007; 28:1155-61.

11. Brott T, Adams HP Jr, Olinger CP, Marler JR, Barsan WG, Biller J, et al, Measurements of acute cerebral infarction: a clinical examination scale. Stroke. 1989;20:864-70.

12. Lyden PD, Lau GT. A critical appraisal of stroke evaluation and rating scales. Stroke. 1991;22:1345-52.

13. Durack DT, Lukes AS, Bright DK. New criteria for diagnosis of infective endocarditis: Utilization of specific echocardiographic findings. Duke endocarditis service. Am J Med. 1994:96:200-9.

14. Li JS, Sexton DJ, Mick N, Nettles R, Fowler VG Jr, Ryan T, et al. Proposed modifications to the duke criteria for the diagnosis of infective endocarditis. Clin Infect Dis. 2000;30:633-8.

15. Roques F, Michel P, Goldstone AR, Nashef SA. The logistic euroscore. Eur Heart J. 2003;24:881-2.

16. Adams HP Jr, Bendixen BH, Leira E, Chang KC, Davis PH, Woolson RF, et al. Antithrombotic treatment of ischemic stroke among patients with occlusion or severe stenosis of the internal carotid artery: a report of the Trial of Org 10172 in Acute Stroke Treatment (TOAST). Neurology. 1999;53:122-5.

17. Bushnell CD, Johnston DC, Goldstein LB. Retrospective assessment of initial stroke severity: comparison of the nih stroke scale and the canadian neurological scale. Stroke. 2001;32:656-60.

18. Williams LS, Yilmaz EY, Lopez-Yunez AM. Retrospective assessment of initial stroke severity with the nih stroke scale. Stroke. 2000;31:858-62.

19. van Swieten JC, Koudstaal PJ, Visser MC, Schouten HJ, van Gijn J. Interobserver agreement for the assessment of handicap in stroke patients. Stroke. 1988;19: 604-7.

20. Hacke W, Kaste M, Fieschi C, von Kummer R, Davalos A, Meier D, et al Randomised double-blind placebo-controlled trial of thrombolytic therapy with intravenous alteplase in acute ischaemic stroke (ECASS II). Second EuropeanAustralasian Acute Stroke Study Investigators. Lancet. 1998;352:1245-51.

21. Robins JM, Hernan MA, Brumback B. Marginal structural models and causal inference in epidemiology. Epidemiology. 2000;11:550-60.

22. Cole SR, Hernan MA. Adjusted survival curves with inverse probability weights Comput Methods Programs Biomed. 2004;75:45-9.

23. Nishimura RA, Otto CM, Bonow RO, Carabello BA, Erwin JP III, Guyton RA, et al. $2014 \mathrm{aha} / \mathrm{acc}$ guideline for the management of patients with valvular heart disease: a report of the American College of Cardiology/American Heart Association Task Force on practice guidelines. J Thorac Cardiovasc Surg. 2014;148: e1-132.

24. Barsic B, Dickerman S, Krajinovic V, Pappas P, Altclas J, Carosi G, et al. Influence of the timing of cardiac surgery on the outcome of patients with infective endocarditis and stroke. Clin Infect Dis. 2013;56:209-17.

25. Yoshioka D, Sakaguchi T, Yamauchi T, Okazaki S, Miyagawa S, Nishi H, et al Impact of early surgical treatment on postoperative neurologic outcome for active infective endocarditis complicated by cerebral infarction. Ann Thorac Surg. 2012;94:489-95. 
26. Baddour LM, Wilson WR, Bayer AS, Fowler VG Jr, Bolger AF, Levison ME, et al. Infective endocarditis: diagnosis, antimicrobial therapy, and management of complications: a statement for healthcare professionals from the Committee on Rheumatic Fever, Endocarditis, and Kawasaki Disease, Council on Cardiovascular Disease in the Young, and the Councils on Clinical Cardiology, Stroke, and Cardiovascular Surgery and Anesthesia, American Heart Association: Endorsed by the Infectious Diseases Society Of America. Circulation. 2005; 111:e394-434.

27. Vilacosta I, Graupner C, San Roman JA, Sarria C, Ronderos R, Fernandez C, et al. Risk of embolization after institution of antibiotic therapy for infective endocarditis. J Am Coll Cardiol. 2002;39:1489-95.

28. Eishi K, Kawazoe K, Kuriyama Y, Kitoh Y, Kawashima Y, Omae T. Surgical management of infective endocarditis associated with cerebral complications. Multi-center retrospective study in Japan. J Thorac Cardiovasc Surg. 1995; 110:1745-55.
29. Gillinov AM, Shah RV, Curtis WE, Stuart RS, Cameron DE, Baumgartner WA, et al. Valve replacement in patients with endocarditis and acute neurologic deficit. Ann Thorac Surg. 1996;61:1125-9; discussion 1130.

30. Tissue plasminogen activator for acute ischemic stroke. The National Institute Of Neurological Disorders and Stroke rt-PA Stroke Study Group. N Engl J Med. 1995;333:1581-7.

31. Tleyjeh IM, Baddour LM. The potential impact of survivor treatment selection bias on the perceived efficacy of valve surgery in the treatment of infective endocarditis. Clin Infect Dis. 2007;44:1392-3.

32. Aksoy O, Sexton DJ, Wang A, Pappas PA, Kourany W, Chu V, et al. Early surgery in patients with infective endocarditis: a propensity score analysis. Clin Infect Dis. 2007;44:364-72.

Key Words: infective endocarditis, stroke, surgery

Readers who found these articles interesting may also like to read the following papers found in recent and future issues of our sister publications, Seminars in Thoracic and Cardiovascular Surgery and Operative Techniques in Thoracic and Cardiovascular Surgery!

\section{Acquired: Endocarditis}

Aminoglycosides For Surgically Treated Enterococcal Endocarditis. Jona M. Banzon. Semin Thoracic Surg 2016: 331-338.

Aminoglycosides for Surgically Treated Enterococcal Endocarditis: A Contemporary Reassessment. David D. Yuh. Semin Thoracic Surg 2016: 339-340. 


\section{APPENDIX E1}

\section{Statistical Analysis}

For the estimation of the propensity score, we used a logistic regression model in which the treatment status (early surgery) was regressed based on the following baseline characteristics: age, sex, smoking history, aortic valve involvement, mitral valve involvement, aortic and mitral valve involvement, prosthetic valve endocarditis, abscess formation, large vegetation, cerebral infarction, cerebral hemorrhage, baseline National Institutes of Health Stroke Scale (NIHSS), and baseline Glasgow Coma Scale score. The resulting c-index was 0.751 , indicating excellent discrimination. The inverse probability treatment weighting method based on the propensity score was used to reduce confounding in time-to-event observational data. With this technique, weights for patients receiving conventional treatment were the inverse of 1 minus the propensity score, and weights for patients receiving early surgery were the inverse of the propensity score.

\section{Comparison of Patient Characteristics Between Patients who were Lost to Follow-up and Those who Completed Followed-up}

Table E1 shows baseline characteristics according to whether patients were lost to follow-up. The clinical characteristics regarding background characteristics, vegetation sites, pathogens, and cerebral complications were similar in the lost to follow-up group and followed-up groups. There were more patients with nonsevere strokes in the lost to follow-up than followed-up group and logistic European System for Cardiac Operative Risk Evaluation scores were lower in the lost to follow-up group.

\section{NIHSS Score and All-Cause Death}

To minimize the survival treatment effect, we considered death and surgical intervention as competing risks and fitted subdistribution hazard models for death and surgical intervention with the NIHSS score as a continuous variable. We found that the hazard ratio of the NIHSS score from the subdistribution model for death was 1.05 (95\% confidence interval 1.03-1.08, $P<.001)$. This finding suggests that a greater NIHSS score is associated with greater allcause mortality.

\section{Baseline Characteristics and Clinical Outcomes According to Study Term}

Because we analyzed our very long-term experience of IE treatment, clinical practice and patients' characteristics might have changed during the study period. Therefore, we divided the study period into 2 terms and assessed the baseline characteristics and outcomes according to these terms (Table E2). We found that the mean age of patients and use of magnetic resonance imaging was significantly greater in the later term than in the earlier term. Features of cerebral complications were not significantly different between these terms. Although operative timing was significantly earlier in the later term than in the earlier term, there were no significant differences in clinical outcomes between the terms, except for all-cause death.

\section{Baseline Characteristics, Imaging Findings, and Clinical Outcomes According to Stroke Symptoms}

Table E3 shows the relationships between imaging findings and NIHSS stratifications. In our study, 79 (46\%) patients were asymptomatic (NIHSS score $=0$ ). Of these, $54(68 \%)$ patients had cerebral infarction and $36(46 \%)$ patients had cerebral hemorrhage. Of the 54 patients with cerebral infarction, $32(59 \%)$ patients underwent early surgery. Only one patient died after the operation, and 28 $(88 \%)$ patients were discharged without significant disability. In the 36 patients with cerebral hemorrhage, however, $17(47 \%)$ patients underwent early surgery and there was no in-hospital mortality. Only one $(6 \%)$ patient was discharged with modified Rankin Scale of 5, whereas the remaining $16(94 \%)$ patients were discharged with full neurologic recovery.

Table E4 shows baseline characteristics and clinical outcomes according to stroke symptoms. Although the proportion of patients who underwent early surgery was similar between symptomatic and asymptomatic patients, there were no significant differences in postoperative cerebral infarction and hemorrhage between these 2 types of patients. However, asymptomatic patients had a significantly better clinical outcome than symptomatic patients.

\section{Baseline Characteristics and Clinical Outcomes According to Timing of Stroke Diagnosis}

Table E5 shows baseline characteristics and clinical outcomes according to the timing of stroke diagnosis. In patients in whom stroke was diagnosed simultaneously with or before IE, there were more symptomatic patients and less patients showed a full neurologic recovery than patients in whom stroke was diagnosed later.

\section{Agreement of Prospective and Retrospective NIHSS}

To assess agreement of prospective and retrospective NIHSS score, we retrospectively analyzed NIHSS score in the 18 patients in whom the NIHSS was assessed prospectively by neurologists. As a result, we found that agreement also was nearly perfect for prospective and retrospective NIHSS scores in the 18 patients in whom the NIHSS was assessed by a neurologist $\left(r=0.97, r^{2}=0.94\right.$, beta $=1.04,95 \%$ confidence interval beta, $0.89-1.16$, $P<.001)$. Retrospective NIHSS scores were not significantly different from prospective NIHSS scores (mean, 11.1 and 11.5, respectively; median, 12.5 and 12.5 , 
respectively; $P=.32$ by the Wilcoxon signed rank test), which indicated no systematic bias in retrospective scoring.

\section{Postoperative Clinical Outcomes in Patients With Nonsevere Hemorrhagic Stroke}

There were no significant differences in postoperative adverse events and clinical outcomes between patients with or without hemorrhagic stroke in both early surgery group and conventional treatment group (Table E6).

\section{Predictors of Poor Modified Rankin Scale at Discharge in Patients With Nonsevere Stroke}

The results of univariate and multivariate logistic regression analyses of predictors of poor modified Rankin Scale at discharge in patients with nonsevere stroke are listed in Table E7. Multivariate analysis revealed that renal failure, European System for Cardiac Operative Risk Evaluation scores, NIHSS score, and conventional treatment were significant predictors of poor modified Rankin Scale at discharge. 


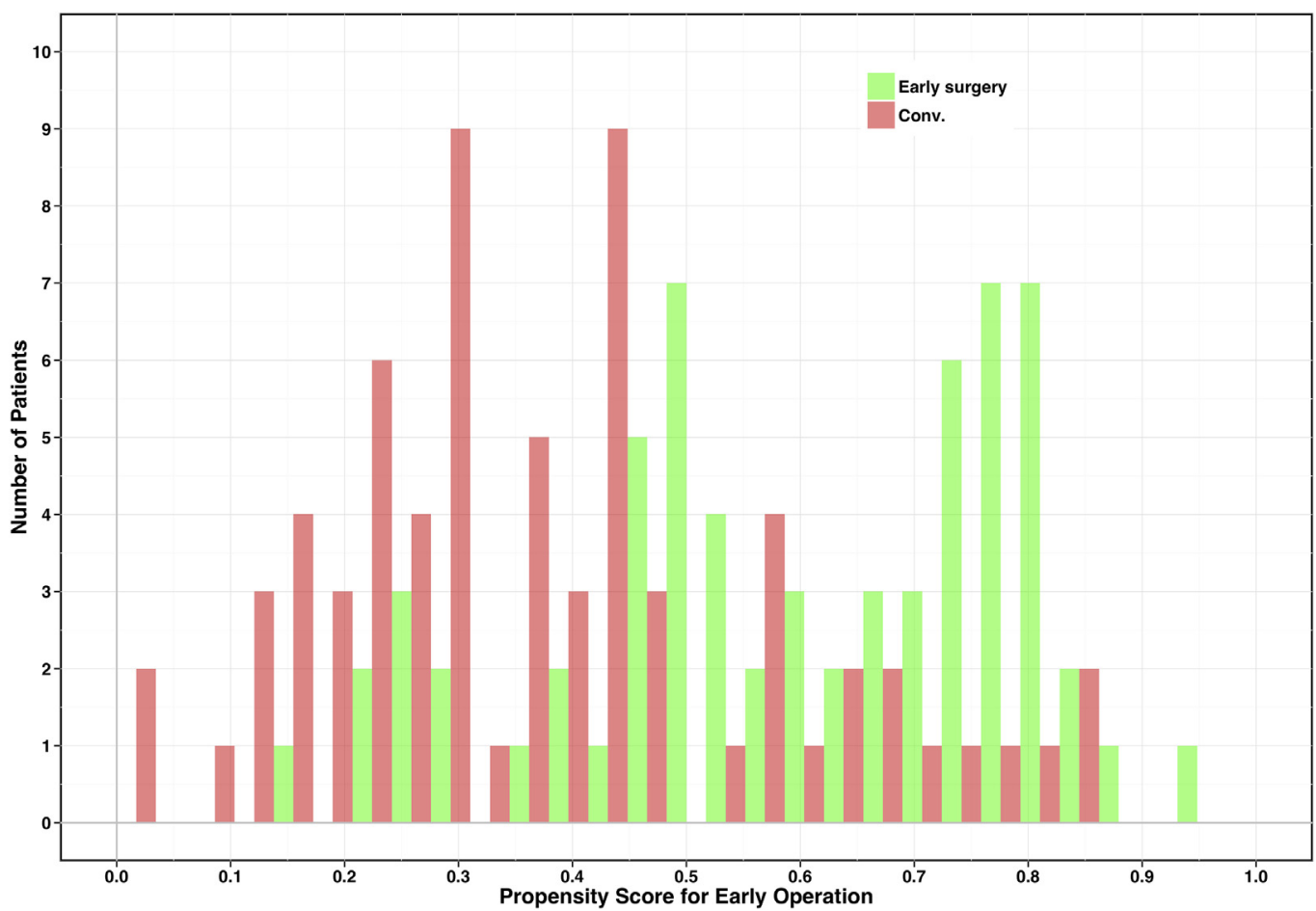

FIGURE E1. Propensity scores for early operation in the early operation and conventional treatment population. Conv., Conventional treatment. 
TABLE E1. Patient characteristics between patients who were lost to follow-up and followed-up

\begin{tabular}{|c|c|c|c|}
\hline & Lost to follow-up group $(n=38)$ & Followed-up group $(n=132)$ & $\boldsymbol{P}$ \\
\hline \multicolumn{4}{|l|}{ Background } \\
\hline Age, $y$, mean $\pm S D$ & $58 \pm 17$ & $61 \pm 17$ & .354 \\
\hline Male, n (\%) & $23(61)$ & $70(53)$ & .413 \\
\hline $\mathrm{HT}, \mathrm{n}(\%)$ & $11(29)$ & $40(30)$ & .872 \\
\hline DM, n $(\%)$ & $9(24)$ & $18(14)$ & .135 \\
\hline Renal failure $(\mathrm{Cr}>2.0 \mathrm{mg} / \mathrm{dL}), \mathrm{n}(\%)$ & $9(24)$ & $22(17)$ & .324 \\
\hline Dialysis, n (\%) & $3(8)$ & $14(11)$ & .445 \\
\hline History of IE, n (\%) & $1(3)$ & $12(9)$ & .163 \\
\hline \multicolumn{4}{|l|}{ Vegetation site } \\
\hline Aortic, n (\%) & $14(37)$ & $59(45)$ & .389 \\
\hline Mitral, n (\%) & $29(76)$ & $97(73)$ & .726 \\
\hline Aortic and mitral, $\mathrm{n}(\%)$ & $5(13)$ & $27(20)$ & .311 \\
\hline PVE, n (\%) & $3(8)$ & $25(19)$ & .106 \\
\hline Vegetation $>10 \mathrm{~mm}, \mathrm{n}(\%)$ & $23(61)$ & $89(67)$ & .429 \\
\hline Abscess, n (\%) & $5(13)$ & $23(17)$ & .532 \\
\hline \multicolumn{4}{|l|}{ Pathogens } \\
\hline Streptococcus spp., n (\%) & $8(21)$ & $45(34)$ & .126 \\
\hline Staphylococcus spp., n (\%) & $19(50)$ & $47(36)$ & .109 \\
\hline \multicolumn{4}{|l|}{ Cerebral complication } \\
\hline Cerebral infarction, $\mathrm{n}(\%)$ & $32(84)$ & $93(70)$ & .090 \\
\hline Cerebral hemorrhage, $\mathrm{n}(\%)$ & $11(29)$ & $54(41)$ & .181 \\
\hline Brain abscess, $\mathrm{n}(\%)$ & $5(13)$ & $8(6)$ & .136 \\
\hline NIHSS, median (IQR) & $1(0-5)$ & $1(0-9)$ & .837 \\
\hline NIHSS $\leq 10$ & $35(92)$ & $102(77)$ & .042 \\
\hline \multicolumn{4}{|l|}{ Operations } \\
\hline Operation during initial admission, $\mathrm{n}(\%)$ & $29(76)$ & $88(67)$ & .258 \\
\hline Early surgery, n (\%) & $18(47)$ & $58(44)$ & .708 \\
\hline \multicolumn{4}{|l|}{ Others } \\
\hline EuroSCORE logistic, \%, median (IQR) & $8.3(4.4-30.5)$ & $16.8(6.8-32.6)$ & .016 \\
\hline Follow-up period, y, mean \pm SD & $5.8 \pm 5.6$ & $3.9 \pm 5.1$ & .053 \\
\hline In-hospital death, $\mathrm{n}(\%)$ & $0(0)$ & $38(29)$ & $<.001$ \\
\hline Full neurologic recovery at discharge, ${ }^{*} \mathrm{n}(\%)$ & $26(68)$ & $68(52)$ & .065 \\
\hline
\end{tabular}

$H T$, Hypertension; $D M$, diabetes mellitus; $C r$, creatinine; $I E$, infective endocarditis; $P V E$, prosthetic valve endocarditis; NIHSS, National Institutes of Health Stroke Scale; EuroSCORE, European System for Cardiac Operative Risk Evaluation; $I Q R$, interquartile range; $S D$, standard deviation. *Modified Rankin Scale $\leq 1$. 
TABLE E2. Baseline characteristics and clinical outcomes according to study term

\begin{tabular}{|c|c|c|c|c|}
\hline & All $(\mathbf{n}=\mathbf{1 7 0})$ & Term 1, 1990-2004 $(n=60)$ & Term 2, 2005- $(n=110)$ & $\boldsymbol{P}$ \\
\hline \multicolumn{5}{|l|}{ Background } \\
\hline Age, $y$, mean \pm SD & $60 \pm 17$ & $54 \pm 17$ & $64 \pm 17$ & $<.001$ \\
\hline Male, n (\%) & $93(55)$ & $34(57)$ & $59(54)$ & .705 \\
\hline $\mathrm{HT}, \mathrm{n}(\%)$ & $51(30)$ & $7(12)$ & $44(40)$ & $<.001$ \\
\hline $\mathrm{DM}, \mathrm{n}(\%)$ & $27(16)$ & $10(17)$ & $17(15)$ & .836 \\
\hline Renal failure $(\mathrm{Cr}>2.0 \mathrm{mg} / \mathrm{dL}), \mathrm{n}(\%)$ & $31(18)$ & $10(17)$ & $21(19)$ & .696 \\
\hline Dialysis, n (\%) & $17(10)$ & $4(7)$ & $13(12)$ & .285 \\
\hline History of IE, n (\%) & $13(8)$ & $6(10)$ & $7(6)$ & .394 \\
\hline \multicolumn{5}{|l|}{ Vegetation site } \\
\hline Aortic, n (\%) & $73(43)$ & $24(40)$ & $49(45)$ & .567 \\
\hline Mitral, n (\%) & $126(74)$ & $47(78)$ & $79(72)$ & .354 \\
\hline Aortic and mitral, $\mathrm{n}(\%)$ & $32(19)$ & $11(18)$ & $21(19)$ & .904 \\
\hline PVE, n (\%) & $28(16)$ & $9(15)$ & $19(17)$ & .703 \\
\hline Vegetation $>10 \mathrm{~mm}, \mathrm{n}(\%)$ & $112(66)$ & $35(58)$ & $77(70)$ & .125 \\
\hline Abscess, n (\%) & $28(16)$ & $8(13)$ & $20(18)$ & .415 \\
\hline \multicolumn{5}{|l|}{ Pathogens } \\
\hline Streptococcus spp., $\mathrm{n}(\%)$ & $66(39)$ & $20(33)$ & $46(42)$ & .278 \\
\hline Staphylococcus spp., n (\%) & $53(31)$ & $20(33)$ & $33(30)$ & .654 \\
\hline \multicolumn{5}{|l|}{ Cerebral complication } \\
\hline Head CT, n (\%) & $124(73)$ & $55(92)$ & $69(63)$ & $<.001$ \\
\hline Head MRI, n (\%) & $137(81)$ & $35(58)$ & $102(93)$ & $<.001$ \\
\hline Cerebral infarction, $\mathrm{n}(\%)$ & $125(74)$ & $42(70)$ & $83(75)$ & .441 \\
\hline Symptomatic CI, n (\%) & $75(44)$ & $30(50)$ & $45(41)$ & .254 \\
\hline Hemorrhagic CI, n (\%) & $11(6)$ & $6(10)$ & $5(5)$ & .146 \\
\hline Cerebral hemorrhage, $\mathrm{n}(\%)$ & $65(38)$ & $19(32)$ & $46(42)$ & .193 \\
\hline Symptomatic ICH, n (\%) & $28(16)$ & $11(18)$ & $17(15)$ & .629 \\
\hline Brain abscess, n (\%) & $13(8)$ & $6(10)$ & $7(6)$ & .286 \\
\hline NIHSS, mean (IQR) & $1(0-7)$ & $2(0-8)$ & $0(0-6)$ & .051 \\
\hline 0 point & $79(46)$ & $20(33)$ & $59(54)$ & \\
\hline $1-3$ points & $30(18)$ & $15(25)$ & $15(14)$ & \\
\hline 4-10 points & $28(16)$ & $13(22)$ & $15(14)$ & \\
\hline $11-15$ points & $9(5)$ & $4(7)$ & $5(5)$ & \\
\hline $16-22$ points & $11(6)$ & $2(3)$ & $9(6)$ & \\
\hline $22-42$ points & $13(8)$ & $6(10)$ & $7(6)$ & \\
\hline Retrospective NIHSS, n (\%) & $152(89)$ & $57(95)$ & $95(86)$ & .080 \\
\hline \multicolumn{5}{|l|}{ Others } \\
\hline EuroSCORE logistic, \%, median (IQR) & $15.2(6.0-31.4)$ & $7.6(4.7-16.0)$ & $20.6(8.6-37.1)$ & $<.001$ \\
\hline \multicolumn{5}{|l|}{ Operations } \\
\hline Operation during initial admission, $\mathrm{n}(\%)$ & $117(69)$ & $47(78)$ & $70(64)$ & .048 \\
\hline Operative timing, ${ }^{*} \mathrm{~d}$, median (IQR) & $8(4-21)$ & $15(7-42)$ & $5(2-11)$ & .007 \\
\hline Early surgery, n (\%) & $76(45)$ & $21(35)$ & $55(50)$ & .060 \\
\hline Postoperative CI, n (\%) $\dagger$ & $10(8)$ & $5(11)$ & $5(7)$ & .358 \\
\hline Postoperative cerebral hemorrhage, $\mathrm{n}(\%) \dagger$ & $17(14)$ & $9(19)$ & $8(11)$ & .177 \\
\hline Postoperative neurologic worsening, $\mathrm{n}(\%) \dagger$ & $25(21)$ & $11(23)$ & $14(20)$ & .398 \\
\hline Symptomatic neurologic worsening, $\mathrm{n}(\%) \dagger$ & $14(12)$ & $8(17)$ & $6(8)$ & .132 \\
\hline \multicolumn{5}{|l|}{ Clinical outcome } \\
\hline Lost follow-up, n (\%) & $38(22)$ & $20(33)$ & $18(16)$ & .011 \\
\hline Follow-up duration, y, mean $\pm \mathrm{SD}$ & $4.3 \pm 5.3$ & $7.5 \pm 7.0$ & $2.6 \pm 2.8$ & $<.001$ \\
\hline In-hospital death, $\mathrm{n}(\%)$ & $38(23)$ & $15(25)$ & $23(21)$ & .541 \\
\hline Full neurologic recovery at discharge, $\ddagger \mathrm{n}(\%)$ & $94(55)$ & $32(53)$ & $62(56)$ & .704 \\
\hline All-cause death, n (\%) & $61(36)$ & $28(47)$ & $33(30)$ & .030 \\
\hline IE-related death, n (\%) & $50(29)$ & $21(35)$ & $29(26)$ & .238 \\
\hline Recurrence of IE, n (\%) & $10(6)$ & $3(5)$ & $7(6)$ & .504 \\
\hline Repeat surgery, n (\%) & $13(8)$ & $5(8)$ & $8(7)$ & .511 \\
\hline
\end{tabular}

$H T$, Hypertension; $D M$, diabetes mellitus; $C r$, creatinine; $I E$, infective endocarditis; $P V E$, prosthetic valve endocarditis; $C T$, computed tomography; $M R I$, magnetic resonance imaging; $C I$, cerebral infarction; ICH, intracerebral hemorrhage; NIHSS, National Institutes of Health Stroke Scale; IQR, interquartile range; EuroSCORE, European System for Cardiac Operative Risk Evaluation. *Days after onset. †Among patients who underwent surgery. $\ddagger$ Modified Rankin scale $\leq 1$. 
TABLE E3. NIHSS groups and details of CNS complications

\begin{tabular}{|c|c|c|c|c|c|c|}
\hline & \multicolumn{6}{|c|}{ NIHSS score } \\
\hline & $\mathbf{0}(\mathbf{n}=79)$ & $1-3(n=30)$ & 4-10 $(n=28)$ & $11-15(n=9)$ & $16-22(n=11)$ & $>22(n=13)$ \\
\hline Cerebral infarction & $54(68)$ & $24(80)$ & $22(79)$ & $9(100)$ & $8(73)$ & $8(62)$ \\
\hline Hemorrhagic infarction & $3(4)$ & $4(13)$ & $2(7)$ & $2(22)$ & $0(0)$ & $0(0)$ \\
\hline Cerebral hemorrhage & $36(46)$ & $6(20)$ & $8(29)$ & $3(33)$ & $6(55)$ & $6(46)$ \\
\hline Hemorrhagic stroke & $38(48)$ & $9(30)$ & $10(36)$ & $3(33)$ & $6(55)$ & $6(46)$ \\
\hline Brain abscess & $5(6)$ & $3(10)$ & $4(14)$ & $0(0)$ & $0(0)$ & $1(8)$ \\
\hline
\end{tabular}

NIHSS, National Institutes of Health Stroke Scale; $C N S$, central nervous system.

TABLE E4. Baseline characteristics and clinical outcomes between asymptomatic and symptomatic patients

\begin{tabular}{|c|c|c|c|}
\hline & Asymptomatic $(n=79)$ & Symptomatic $(\mathbf{n}=91)$ & $\boldsymbol{P}$ \\
\hline \multicolumn{4}{|l|}{ Background } \\
\hline Age, $y$, mean \pm SD & $60 \pm 17$ & $60 \pm 18$ & .860 \\
\hline Male, $n(\%)$ & $44(56)$ & $49(54)$ & .809 \\
\hline $\mathrm{DM}, \mathrm{n}(\%)$ & $13(16)$ & $14(15)$ & .849 \\
\hline Renal failure $(\mathrm{Cr}>2.0 \mathrm{mg} / \mathrm{dL}), \mathrm{n}(\%)$ & $11(14)$ & $20(22)$ & .175 \\
\hline Dialysis, n (\%) & $5(6)$ & $12(13)$ & .137 \\
\hline \multicolumn{4}{|l|}{ Vegetation site } \\
\hline Aortic, n (\%) & $37(47)$ & $36(40)$ & .339 \\
\hline Mitral, n (\%) & $55(70)$ & $71(78)$ & .212 \\
\hline Aortic and mitral, $\mathrm{n}(\%)$ & $15(19)$ & $17(19)$ & .959 \\
\hline PVE, n (\%) & $14(18)$ & $14(15)$ & .682 \\
\hline Vegetation $>10 \mathrm{~mm}, \mathrm{n}(\%)$ & $53(67)$ & $59(65)$ & .757 \\
\hline \multicolumn{4}{|l|}{ Pathogens } \\
\hline Streptococcus spp., $\mathrm{n}(\%)$ & $38(48)$ & $28(31)$ & .021 \\
\hline Staphylococcus spp., n (\%) & $19(24)$ & $34(37)$ & .062 \\
\hline \multicolumn{4}{|l|}{ Cerebral complication } \\
\hline Cerebral infarction, $\mathrm{n}(\%)$ & $54(68)$ & $71(78)$ & .154 \\
\hline Hemorrhagic CI, n (\%) & $3(4)$ & $8(9)$ & .187 \\
\hline Cerebral hemorrhage, $\mathrm{n}(\%)$ & $36(46)$ & $29(32)$ & .067 \\
\hline \multicolumn{4}{|l|}{ Operations } \\
\hline Operation during initial admission, $\mathrm{n}(\%)$ & $62(78)$ & $55(60)$ & .011 \\
\hline Early surgery, n (\%) & $42(53)$ & $34(37)$ & .039 \\
\hline Postoperative cerebral infarction, $\mathrm{n}(\%) *$ & $3(5)$ & $7(13)$ & .112 \\
\hline Postoperative cerebral hemorrhage, $\mathrm{n}(\%) *$ & $9(14)$ & $8(15)$ & .586 \\
\hline \multicolumn{4}{|l|}{ Clinical outcome } \\
\hline In-hospital death, n (\%) & $4(5)$ & $34(37)$ & $<.001$ \\
\hline Full neurologic recovery at discharge, $\nmid \mathrm{n}(\%)$ & $65(82)$ & $29(32)$ & $<.001$ \\
\hline All cause death, n $(\%)$ & $15(19)$ & $46(51)$ & $<.001$ \\
\hline IE-related death, n (\%) & $10(13)$ & $40(44)$ & $<.001$ \\
\hline
\end{tabular}

$D M$, Diabetes mellitus; $C r$, creatinine; $P V E$, prosthetic valve endocarditis; $C I$, cerebral infarction; $I E$, infective endocarditis. *Among patients who underwent surgery. $\dagger$ Modified Rankin scale $\leq 1$. 
TABLE E5. Baseline characteristics and outcomes according to timing of IE and CNS complication diagnosis

\begin{tabular}{|c|c|c|c|c|}
\hline & CNS after IE $(n=68)$ & Simultaneous $(\mathrm{n}=60)$ & IE after CNS $(n=42)$ & $\boldsymbol{P}$ \\
\hline \multicolumn{5}{|l|}{ Background } \\
\hline Age, $y$, mean $\pm S D$ & $61 \pm 16$ & $58 \pm 18$ & $62 \pm 18$ & .521 \\
\hline Male, $\mathrm{n}(\%)$ & $39(57)$ & $31(52)$ & $23(55)$ & .812 \\
\hline $\mathrm{DM}, \mathrm{n}(\%)$ & $10(15)$ & $7(12)$ & $10(24)$ & .241 \\
\hline Renal failure $(\mathrm{Cr}>2.0 \mathrm{mg} / \mathrm{dL}), \mathrm{n}(\%)$ & $8(12)$ & $13(22)$ & $10(24)$ & .196 \\
\hline Dialysis, n (\%) & $5(7)$ & $5(8)$ & $7(17)$ & .248 \\
\hline \multicolumn{5}{|l|}{ Vegetation site } \\
\hline Aortic, n (\%) & $32(47)$ & $26(43)$ & $15(36)$ & .504 \\
\hline Mitral, n (\%) & $48(71)$ & $44(73)$ & $34(81)$ & .476 \\
\hline Aortic and mitral, n (\%) & $15(22)$ & $10(17)$ & $7(17)$ & .678 \\
\hline PVE, n $(\%)$ & $12(18)$ & $9(15)$ & $7(17)$ & .921 \\
\hline Vegetation $>10 \mathrm{~mm}, \mathrm{n}(\%)$ & $43(63)$ & $47(78)$ & $22(52)$ & .021 \\
\hline \multicolumn{5}{|l|}{ Pathogens } \\
\hline Streptococcus spp., n (\%) & $28(41)$ & $24(40)$ & $14(33)$ & .695 \\
\hline Staphylococcus spp., n (\%) & $17(25)$ & $20(33)$ & $16(38)$ & .320 \\
\hline \multicolumn{5}{|l|}{ Cerebral complication } \\
\hline Cerebral infarction, $\mathrm{n}(\%)$ & $43(63)$ & $52(87)$ & $30(71)$ & .011 \\
\hline Symptomatic CI, n (\%) & $17(25)$ & $29(48)$ & $29(69)$ & $<.001$ \\
\hline Hemorrhagic CI, n (\%) & $6(9)$ & $4(7)$ & $1(2)$ & .409 \\
\hline Cerebral hemorrhage, $\mathrm{n}(\%)$ & $37(54)$ & $18(30)$ & $10(24)$ & .002 \\
\hline Symptomatic ICH, n (\%) & $11(16)$ & $9(15)$ & $8(19)$ & .860 \\
\hline Brain abscess, $\mathrm{n}(\%)$ & $5(7)$ & $1(2)$ & $7(17)$ & .019 \\
\hline \multicolumn{5}{|l|}{ Operations } \\
\hline Operation during initial admission, $\mathrm{n}(\%)$ & $49(72)$ & $44(73)$ & $24(57)$ & .168 \\
\hline Early surgery, n (\%) & $27(39)$ & $36(60)$ & $13(31)$ & .008 \\
\hline \multicolumn{5}{|l|}{ Clinical outcome } \\
\hline In-hospital death, n (\%) & $11(16)$ & $16(27)$ & $11(26)$ & .287 \\
\hline Full neurologic recovery at discharge, ${ }^{*} \mathrm{n}(\%)$ & $46(68)$ & $33(55)$ & $15(36)$ & .005 \\
\hline All cause death, n $(\%)$ & $21(31)$ & $21(35)$ & $19(45)$ & .308 \\
\hline IE-related death, n (\%) & $14(21)$ & $19(32)$ & $17(40)$ & .075 \\
\hline
\end{tabular}

CNS after IE: Stroke was diagnosed after the diagnosis of IE. Simultaneous: Stroke was simultaneously diagnosed with the diagnosis of IE. IE after CNS: Stroke was diagnosed before the diagnosis of IE. IE, Infective endocarditis; $C N S$, central nervous system; $D M$, diabetes mellitus; $C r$, creatinine; $P V E$, prosthetic valve endocarditis; $C I$, cerebral infarction; $I C H$, intracerebral hemorrhage. *Modified Rankin scale $\leq 1$.

TABLE E6. Postoperative adverse events and clinical outcomes in patients with nonsevere stroke according to treatment strategy and hemorrhagic stroke

\begin{tabular}{|c|c|c|c|c|c|c|}
\hline & \multicolumn{3}{|c|}{ Early surgery $(\mathrm{n}=65)$} & \multicolumn{3}{|c|}{ Conventional treatment $(n=72)$} \\
\hline & $\begin{array}{l}\text { Hemorrhagic } \\
\quad(n=25)\end{array}$ & $\begin{array}{l}\text { Nonhemorrhagic } \\
\quad(n=40)\end{array}$ & $\boldsymbol{P}$ & $\begin{array}{l}\text { Hemorrhagic } \\
\quad(n=32)\end{array}$ & $\begin{array}{l}\text { Nonhemorrhagic } \\
(\mathbf{n}=\mathbf{4 0})\end{array}$ & $\boldsymbol{P}$ \\
\hline NIHSS, median (IQR) & $0(0-1)$ & $0(0-3)$ & .430 & $0(0-3)$ & $2(0-4)$ & .119 \\
\hline Operation during initial admission, $\mathrm{n}(\%)$ & $25(100)$ & $40(100)$ & 1.000 & $20(63)$ & $17(43)$ & .092 \\
\hline Postoperative neurologic worsening, ${ }^{*} \mathrm{n}(\%)$ & $6(24)$ & $11(28)$ & .755 & $2(10)$ & $2(12)$ & 1.000 \\
\hline Postoperative cerebral infarction, ${ }^{*} \mathrm{n}(\%)$ & $3(12)$ & $6(15)$ & .520 & $0(0)$ & $1(6)$ & .459 \\
\hline Postoperative cerebral hemorrhage, $*$ n $(\%)$ & $4(16)$ & $6(15)$ & .589 & $2(10)$ & $1(6)$ & 1.000 \\
\hline Symptomatic neurologic worsening, ${ }^{*} \mathrm{n}(\%)$ & $3(12)$ & $6(15)$ & .520 & $1(5)$ & $1(6)$ & 1.000 \\
\hline In-hospital death, $\mathrm{n}(\%)$ & $0(0)$ & $2(5)$ & .375 & $7(22)$ & $10(25)$ & .756 \\
\hline All-cause death, n $(\%)$ & $2(8)$ & $9(23)$ & .118 & $12(38)$ & $16(40)$ & .829 \\
\hline MACE, n (\%) & $3(12)$ & $12(30)$ & .094 & $12(38)$ & $18(45)$ & .521 \\
\hline IE death, n $(\%)$ & $1(4)$ & $6(15)$ & .165 & $8(25)$ & $15(38)$ & .258 \\
\hline IE recurrence, $\mathrm{n}(\%)$ & $0(0)$ & $5(13)$ & .080 & $1(3)$ & $2(5)$ & .584 \\
\hline Repeat surgery, n (\%) & $1(4)$ & $6(15)$ & .165 & $3(9)$ & $1(3)$ & .228 \\
\hline
\end{tabular}

NIHSS, National Institutes of Health Stroke Scale; IQR, interquartile range; $M A C E$, major adverse cardiac events; $I E$, infective endocarditis. *Among patients who underwent surgery. 
TABLE E7. Univariable and multivariable analysis of predictors of poor modified Rankin scale in patients with nonsevere stroke

\begin{tabular}{|c|c|c|c|c|}
\hline & \multicolumn{2}{|c|}{ Univariable predictors } & \multicolumn{2}{|c|}{ Multivariable predictors } \\
\hline & Odds ratio $(95 \% \mathrm{CI})$ & $\boldsymbol{P}$ & Odds ratio $(95 \%$ CI $)$ & $\boldsymbol{P}$ \\
\hline Age & $1.04(1.02-1.07)$ & .002 & - & - \\
\hline Hypertension & $2.58(1.17-5.70)$ & .019 & - & - \\
\hline Renal failure $(\mathrm{Cr}>2.0 \mathrm{mg} / \mathrm{dL})$ & $7.28(2.88-18.39)$ & $<.001$ & $5.66(1.93-16.64)$ & .002 \\
\hline Dialysis, n (\%) & $16.33(4.27-62.48)$ & $<.001$ & - & - \\
\hline EuroSCORE logistic & $1.07(1.04-1.10)$ & $<.001$ & $1.07(1.03-1.10)$ & $<.001$ \\
\hline NIHSS & $1.31(1.12-1.51)$ & $<.001$ & $1.34(1.10-1.64)$ & .004 \\
\hline Symptomatic cerebral infarction & $2.96(1.35-6.48)$ & .007 & - & - \\
\hline Conventional treatment & $3.11(1.36-7.11)$ & .007 & $3.34(1.17-9.51)$ & .024 \\
\hline
\end{tabular}

CI, Confidence interval; $C r$, creatinine; EuroSCORE, European System for Cardiac Operative Risk Evaluation; NIHSS, National Institutes of Health Stroke Scale. 